\title{
Preparation and nitridation of silicon whiskers
}

\author{
P. S. GOPALAKRISHNAN, P. S. LAKSHMINARASIMHAM \\ Materials Science Division, National Aerospace Laboratories, Bangalore 560017 , India
}

Silicon nitride is of great interest as a high temperature ceramic material for use in engine and turbine parts, cutting tools and bearings [1]. To fabricate reliable components out of silicon nitride for these applications it is essential that the starting powder of silicon nitride should have high purity, uniform particle size and high percentage of $\alpha$-phase [2]. Various methods of preparing silicon nitride powder have been discussed by many authors [3-5]. The major problem encountered in the direct nitridation of silicon is that the product is always coarse, necessitating prolonged milling, which causes contamination. In the carbothermal reduction of silica, a very large excess of carbon has to be used, which is removed later by heating in air, but a small amount of carbon always remains as an impurity. In the ammonolysis of silicon halides the intermediate product, silicon imide, is highly sensitive to air and moisture, and complete removal of the halide is also difficult. We have been looking for a process in which these problems are avoided. In this connection one of our interests has been to see whether high purity silicon powder can be prepared from silicon tetrachloride and whether this powder can be nitrided in situ. However, our experiments have not been successful in this regard, but resulted in silicon whiskers and whisker-like silicon nitride. These experiments are reported here.

Metals like magnesium, iron, zinc and cadmium can reduce silicon tetrachloride to silicon. This principle had been used to prepare semiconductor grade silicon. Whiskers of silicon have been prepared by the disproportionation of silicon dibromide [6], gas phase reduction of silicon tetrachloride with hydrogen [7] and thermal decomposition of silane [8]. Our attempts to prepare silicon powder by the reduction of silicon tetrachloride with iron filings resulted in ferrosilicon globules. It was realized that to get silicon powder, a reaction between the metal vapour and silicon tetrachloride vapour has to be employed. Zinc, being a metal with low boiling point, was considered suitable for this purpose. Recently, magnesium vapour has been used to reduce silicon tetrachloride for the preparation of silicon powder [9].

The experiment basically involves production of zinc vapour by heating the metal to its boiling point and reacting this vapour with silicon tetrachloride vapour diluted with nitrogen. A schematic of the experimental set-up is shown in Fig. 1. It consists of a two-zone horizontal furnace; one zone, of length $200 \mathrm{~mm}$, is for generating the zinc vapour and the other, of length $400 \mathrm{~mm}$, is for reacting the zinc

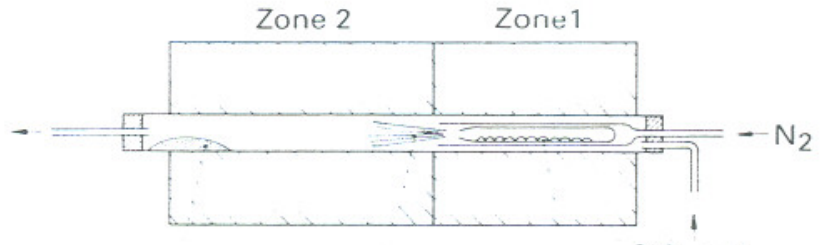

$\mathrm{SiCl}_{4}+\mathrm{N}_{2}$

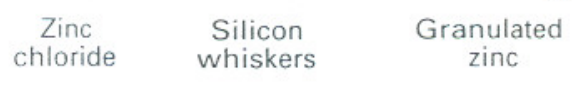

Figure I A schematic diagram of the experimental set-up.

vapour with silicon tetrachloride vapour in the presence of nitrogen. The reaction tube is of fused quartz with diameter $25 \mathrm{~mm}$ and length $1000 \mathrm{~mm}$. About $10 \mathrm{~g}$ of granulated zinc (Analar, BDH) was put in a quartz tube of diameter $15 \mathrm{~mm}$ and length $150 \mathrm{~mm}$ with one end closed and the other end tapered. This was enclosed in a jacket made out of fused quartz with a diameter of $20 \mathrm{~mm}$ and length of $200 \mathrm{~mm}$. This jacket had an inlet through which dry nitrogen could be passed. This was kept in zone 1 of the furnace. The temperature of this zone was increased gradually to above the boiling point of zinc while passing nitrogen at a rate of $11 \mathrm{~min}^{-1}$, through the jacket so that the zinc vapour was carried into the reaction zone (zone 2 of the furnace). The temperature of this zone was maintained between 900 and $1200^{\circ} \mathrm{C}$. Dry nitrogen was bubbled at a rate of $0.51 \mathrm{~min}^{-1}$ through distilled silicon tetrachloride liquid in a bottle, and the gaseous mixture of silicon tetrachloride and nitrogen was passed over the jacket to the reaction zone. The reaction took place according to the equation:

$$
\mathrm{SiCl}_{4}(\mathrm{~g})+2 \mathrm{Zn}(\mathrm{g}) \rightarrow \mathrm{ZnCl}_{2}(\mathrm{~g})+\mathrm{Si}(\mathrm{C})
$$

White fumes of zinc chloride were observed from the outlet of the reaction tube as long as the reaction was taking place. These fumes also condensed at the cooler end of the reacton tube. The temperature of both the zones was reduced after the reaction was over. The product was taken out of the reaction tube after it had cooled to the room temperature. It was observed that the products of the reaction condensed in two distinct regions of the reaction tube. The product that condensed in the cooler region was pure zinc chloride, and the product that condensed in the hot zone consisted of only whiskers. These whiskers were characterized by X-ray diffraction (XRD) and electron microscopy. The XRD pattern confirmed that these whiskers were only crystalline silicon but not silicon nitride. When the temperature of the reaction was $1200{ }^{\circ} \mathrm{C}$, the whiskers were thick 


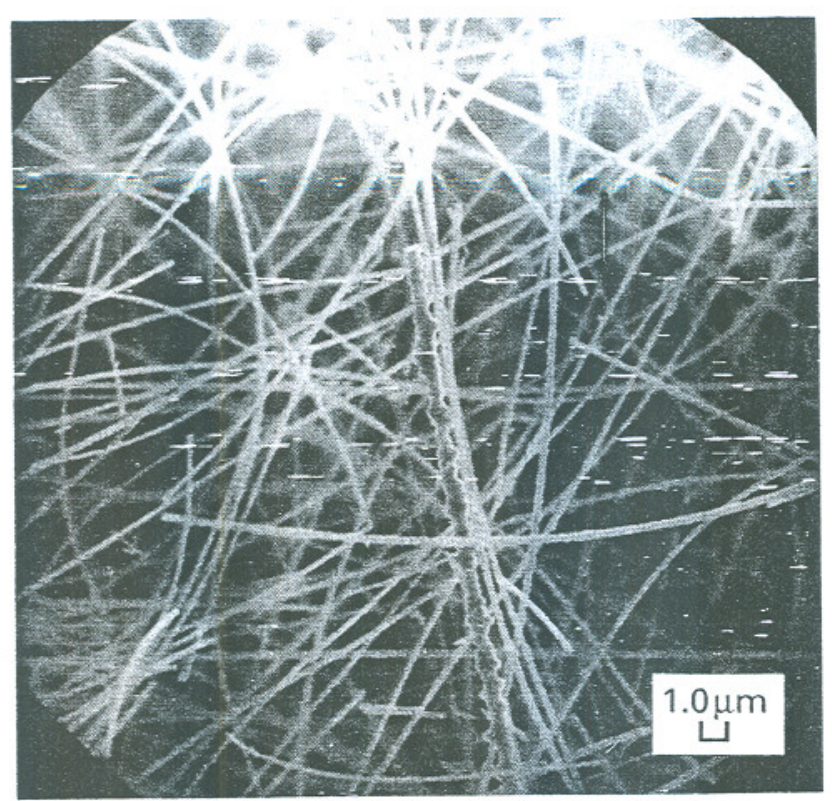

Figure 2 Scanning electron micrograph of the silicon whiskers.

and had the characteristic lustre of silicon. At lower temperature the whiskers were finer and the colour was light brown. When the reaction temperature was $950{ }^{\circ} \mathrm{C}$, the whiskers were very thin and looked like wool, creamy white in colour. An electron micrograph of these whiskers is shown in Fig. 2. The thickness of these whiskers was about $0.5 \mu \mathrm{m}$ and their length was more than $1 \mathrm{~cm}$.

These experiments were repeated with increased nitrogen flow to see whether the whiskers could be nitrided in situ. However, these experiments were not successful in this regard, but the whiskers became still finer, down to a thickness of $0.1 \mu \mathrm{m}$. Therefore, the silicon whiskers were nitrided separately using dry ammonia gas [10] in the temperature range $1200-1300^{\circ} \mathrm{C}$. The XRD and infrared absorption data showed that the product of nitridation was $\alpha$-silicon nitride. An electron micrograph of this silicon nitride is shown in Fig. 3. By comparing this micrograph with that of silicon whiskers, it can be inferred that during the nitridation the silicon whiskers do not become powder, but become shorter, probably pseudomorphs. The thickness.of these pseudomorphs was about $0.5 \mu \mathrm{m}$.

The length is fairly uniform and is about $12 \mu \mathrm{m}$. Such whisker-like particles with uniform aspect ratio may also be useful in ceramic composites.

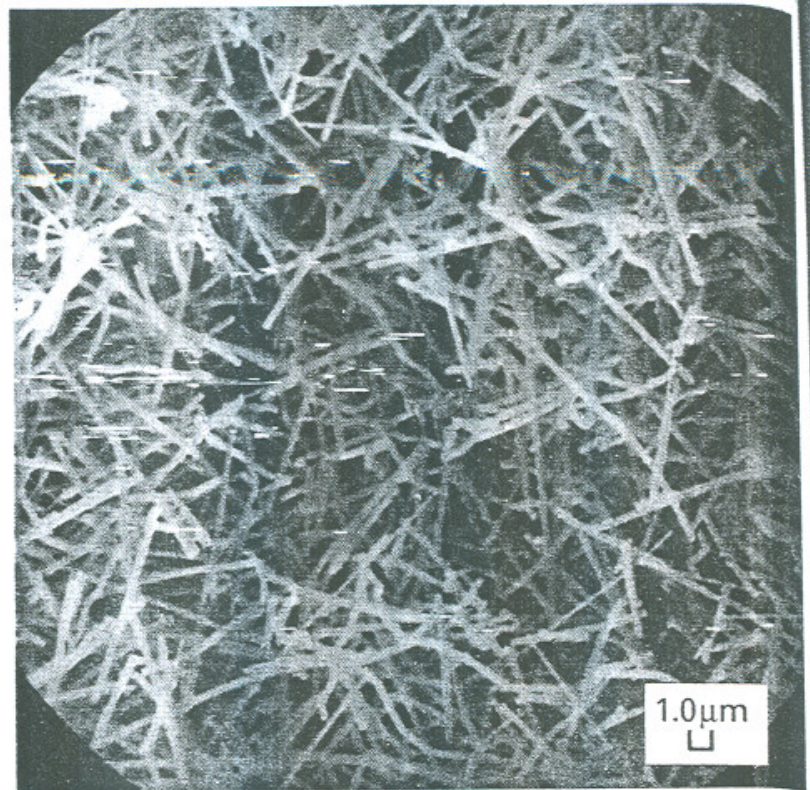

Figure 3 Scanning electron micrograph of the whisker-like silicon nitride.

\section{Acknowledgement}

We thank Mr M. A. Venkataswamy for the electron micrographs.

\section{References}

1. L. M. SHEPPARD, Amer. Ceram. Soc. Bull. 69 (1990) 1012 .

2. W. ENGEL. Powder Met. Int. 10 (1978) 124

3. H. LANGe, G. WOtting and G. Winter, Angew. Chem. Int. Ed. Engl. 30 (1991) 1579.

4. G. M. CROSBIE, R. L. PREDMESKY. J. M. NICHOL. SON and E. D. STILES. Amer. Ceram. Soc. Bull. 68 (1989) 1010 .

5. K. S. MAZDIYASNI and C. M. COOKE, J. Amer. Ceram. Soc. 56 (1973) 628.

6. A. V.SANDULOVA. I. P. BOGOYAVLENSKAYA and L. IPYRSKO. Neorg. Mater. 2 (1966) 1684 (in Russian).

7. T. YOSHIDA, A. SERIKYAKU and M. YOSHIMATSU, Fukuoka Daigaku Rigaku Shuho 16 (1986) 81 (in Japanese).

8. Y. OSADA.H. NAKAYAMA, M. SHINDO, T. ODAKA and Y. OGATA, J. Electrochem. Soc. 126 (1979) 31.

9. B. W, JONG, G. J. SLAVENS and D. E. TRAUT, J. Mater. Sci. 27 (1992) 6086.

10. P. S. GOPALAKRISHNAN and P. S. LAKSHMINARA SIMHAM. J. Mater. Sci. Lett. 12 (1993) 1422.

Received 7 April

and accepted 20 July 1994 